\title{
FOOD-BASED AND NON-FOOD-BASED INTERVENTIONS TO IMPROVE DIETARY DIVERSITY: A LITERATURE REVIEW
}

\author{
Riska Mayang Saputri Ginting ${ }^{1 *}$, Nila Reswari Haryana ${ }^{2}$, Sri Sumarmi ${ }^{3}$ \\ ${ }^{1}$ Faculty of Public Health, Universitas Airlangga, Surabaya, Indonesia \\ ${ }^{2}$ Faculty of Engineering, Nutrition Study Program, State University of Medan, Indonesia \\ ${ }^{3}$ Public Health Research Unit, Faculty of Public Health Universitas Airlangga, Surabaya, Indonesia \\ *E-mail: riskamayangsg@gmail.com
}

\begin{abstract}
Dietary diversity is one of the diet quality. Poor dietary diversity is associated with malnutrition, stunting, poor gut health, pregnancy complications, and cognitive impairment. Overcoming the underlying and basic causes of poor dietary diversity is imperative through policymaking. This current literature review discussed about intervention policies to improve dietary diversity at the individual and population levels. Literature search was carried out in some databases, i.e., Pubmed/Medline, Google Scholar, and Google with key word search such as dietary diversity, improvement, programs, interventions, and policies. The synthesized articles included observational studies, experimental studies, and grey literature on Dietary diversity programs and interventions. Articles on biodiversity and microbial diversity were not included. Dietary diversity can outgrow by knowing the policy on food-based interventions which are closely related to the food system and non-food-based interventions to improve socio-economic aspect and knowledge. Foodbased interventions include food production, food prices, agricultural diversification, market development, and foodbased dietary guidelines. Meanwhile, non-food-based interventions involve a country's development and economic growth, social behavior change, communication strategy, cash transfer, and mass media campaigns. Interventions to improve dietary diversity must be carried out in multi-sectors, for example, by improving family welfare, knowledge and behavior change, and stable food access.
\end{abstract}

Keywords: Dietary diversity, policies, food-based intervention, and non-food-based intervention

\section{INTRODUCTION}

Dietary diversity, which represents a major part of dietary quality, is the amount of food consumed in a food group in a certain period (Arimond et al., 2011). Globally, two out of three children aged 6 to 23 months do not meet the minimum recommended dietary diversity and only consume at least five out of eight food groups in a day. Only Asia and upper-middle-income countries can provide the amount of fruit and vegetables according to $\mathrm{FAO} / \mathrm{WHO}$ recommendations that mention a minimum food intake is $400 \mathrm{~g} /$ person/ day. Less than $40 \%$ of children in seven of eleven subregions (i.e., Southern Africa, Eastern Asia, Northern Africa, Western Africa, Eastern Africa, Southern Africa, and Middle Africa) did not meet the minimum dietary diversity (Food and Agriculture Organization et al., 2020). Dietary diversity in low-income countries and rural areas is lower compared to middle-income countries and urban areas (Choudhury and Headey, 2017; Geng et al., 2018).

The number of food groups consumed is positively related to the adequate macronutrient and micronutrient density and nutritional status (Kennedy et al., 2011; Nithya and Bhavani, 2018). Stunting in under-five children is also known to occur partly due to poor dietary diversity, especially in children at the age of 6-11 months (Oldewage-Theron and Kruger, 2008; Roesler et al., 2019; Utami and Mubasyiroh, 2020). Other effects of poor dietary diversity are cognitive impairment (Otsuka et al., 2017; Yin et al., 2017; Zhang et al., 2020; Zheng et al., 2021) and poor gut health (Heiman and Greenway, 2016; Laitinen and Mokkala, 2019; Valdes et al., 2018). Meanwhile, an adequate intake of dietary diversity helps pregnant women reduce the occurrence of pre-eclampsia, anemia, low birth weight, and premature birth (Agrawal et al., 2015; Zerfu et 
al., 2016). The high dietary diversity may prevent metabolic syndrome because it contributes to reduce low serum triglycerides, systolic blood pressure, and adiponectin serum (Farhangi and Jahangiry, 2018).

Household food diversity is useful to determine the level of resources available in a household. Due to the relevance of dietary diversity as a pillar of food security, several factors i.e., food availability, accessibility, utilization, and stability influence the adequacy of food diversity (Obayelu and Osho, 2020). Poor household and child dietary diversity is closely related to household socioeconomic status, such as low education level, big household size, low household food expenditure, small house size, and poor hygiene and sanitation of toilet facilities and drinking water (CorderoAhiman et al., 2021; Obayelu and Osho, 2020; Powell et al., 2017).

A market has a great influence on the dietary diversity of the population (Ambikapathi et al., 2019; Masters et al., 2018). Households who contract with food markets more frequently are more likely to have diversified diets related to food purchase diversity (Matita et al., 2021). However, a drastic increase in food prices causes a decrease in purchasing power (Cordero-Ahiman et al., 2021; D'Souza and Jolliffe, 2016). Food availability as one of the pillars of food diversity is closely related to agriculture and agrobiodiversity. For instance, it has a relationship with the use of land varieties and landscape heterogeneity. Besides, food availability depends on home garden ownership, seasons, and geography (Custodio et al., 2019; Powell et al., 2017).

Preventions and interventions to improve dietary diversity at the individual and population levels should be carried out through crosssectoral collaborative programs. Many strategies could improve dietary diversity, but there is no categorization of the policies yet. In this review, policies were reviewed based on two broad groups, namely food-based intervention (related to the food system) and non-food-based intervention (related to socio-economic aspects and knowledge). Therefore, it is necessary to improve dietary diversity at the individual and population levels.

\section{METHODS}

This current literature review synthesized several previous studies to gain more understanding about dietary diversity policies and interventions in a broader population. A non-systematic, explorative literature search was conducted in some electronic database platforms such as Google Scholar, Pubmed/Medline, and Google. The synthesized studies included observational studies (cross-sectional, case-control, and cohort), experimental studies, and grey literature which must contain relevant keywords such as dietary diversity or diversification which were searched alone or in combination with several keywords such as interventions, policies, and programs. Those keywords along with their synonyms were obtained using the Boolean search methods. All articles were free accessed full texts published in Indonesian and English. Articles which talked over other topics such as biodiversity, and microbial diversity were excluded.

\section{RESULTS AND DISCUSSION}

\section{Dietary Diversity Improvement Interventions}

Nutrition interventions at the community level can be carried out using two approaches: foodbased and non-food-based nutrition interventions. Food-based interventions have something to do with the food system aimed to improve food production and availability, supply, processing, conservation, commercialization, as well as food access and consumption (Morón, 2006). Meanwhile, non-food-based interventions aim to improve dietary diversity through supporting factors, e.g., socio-economic aspects and knowledge.

These two interventions indicated a multisectoral approach on nutrition interventions could address the underlying causes and basic causes of malnutrition. To comply with quality diets, a diverse diet ensures that each individual has access to food as an adequate source of macro and micronutrients. Nair et al. (2016) found that successful dietary diversity strategies can tackle hidden hunger by integrating the interventions with bioavailability, such as food synergy on 
food accessibility, affordability, and lifestyle modification.

\section{Food-based Intervention Strategy}

\section{Food Production and Supply Management}

Interventions to improve population food diversity can be applied through improved food security (Chiang and Capiña, 2018). Food production and supply management can meet the population needs with sufficient food quantity. Supply management not only includes producers and suppliers but also deals with logistics flows, transporters, warehouses, retailers, and consumers (van der Vorst et al., 2007). Increased food production likely lead to local food availability. Higher production generally means lower food prices and access to greater quantities of food in markets (Dorward, 2014).

Increased crop diversity alone may not be sufficient to ensure more food diversities (Dillon et al., 2015). Better market access in peri-urban and rural areas in smallholder households in Kenya and Tanzania generally result in lower food production diversity, but higher food diversity. Such access can expand opportunities for product sales and purchase of diversified food items (Kissoly et al., 2020). In Indonesia, the control of food production, which reflects the food sufficiency of the population, is carried out by taking into account the level of food availability in an area, either originating from domestic production, reserves/ stocks, or imports (Food Security Agency, 2018). An increase in food availability and control of food stocks leads to improved desirable dietary pattern scores in Indonesia, ranging from 86.2 in 2016 to 92.5 in 2019 (Food Security Agency, 2021).

Homestead food production programs in four Asian countries (Bangladesh, Cambodia, Nepal, and the Philippines) could increase dietary diversification. Moreover, it could result in more frequent vegetable consumption in children by 1.6 times higher through home gardening, animal husbandry, and nutrition education (Talukder et al., 2010).

\section{Agricultural diversity}

Agricultural diversity is "the variety and variability of animals, plants and micro-organisms that are used directly or indirectly for food and agriculture, including crops, livestock, forestry and fisheries" (Dulloo, 2019). Agriculture increases food diversity through diversification of food production by considering the seasons (Habtemariam et al., 2021). Strong agricultural biodiversity can support healthy diets through easy access to diverse crop availability and better soil quality (Chiang and Capiña, 2018). Other interventions related to agricultural production and diversification include subsidies and assistance to distribution, tax deduction, technology, and government-funded farm research. These policies need to be carefully designed and implemented to avoid unintended consequences (Food and Agriculture Organization of the United Nations, 2019).

Agroecological control can improve diversity through swelling small-scale production of micronutrient-rich foods for personal or local consumption and higher commercial production of micronutrient-rich foods (Thompson et al., 2014). Agroecology is the simultaneous application of ecological and social concepts and principles for food and agricultural system design and management (Nannipieri et al., 2002). Such control can also preserve micronutrient levels of commonly eaten foods through reduced postharvest loss and selected breed plants (Thompson et al., 2014).

Indonesia has applied agroecology in its agricultural diversity policy. For example, the country has established a food self-sufficient area program by involving community representatives from selected villages to enforce independent communities through a labor-intensive and stunting reduction in regions prone to food deficiency (Food and Agriculture Organization of the United Nations, 2019).

\section{Food-based Dietary Guidelines}

Food-based dietary guidelines (FBDGs) are valuable tools for nutrition policy and public health strategies to promote healthy eating with various food groups and physical activities. These guidelines aim to increase public awareness of evidence-based healthy eating and lifestyle habits, which are tailored to the eating habits of the target population. More than 100 countries around the world have developed food-based 
dietary guidelines that recommend a variety of foods based on dietary patterns and culture. Some of the holistic approaches often used are the healthy eating pyramid or food pyramid and my plate (Food and Agriculture Organization of the United Nations, 2021). FBGDs are also the basis for assessing the dietary diversity of the population (Verger et al., 2019).

Interdisciplinary experts, including policymakers, legislators, nutrition and other health professionals, have developed dietary guidelines in agriculture, education, consumer science, nongovernment organizations, communications, as well as private sectors such as food and health industries, as well as media (World Health Organization, 1998). Before being distributed to the target population, the guidelines will be tested to ensure practicability and comprehensiveness. The target population of the FBDGs should include the general population, infants, children, adults, pregnant and lactating mothers, and elderly. Certain dietary preference groups i.e., vegetarians and people with diseases e.g., cardiovascular disorders and diabetes require special diets (World Health Organization, 2011).

\section{Food Price Controls}

High food price volatility (significant and frequent changes in the direction and magnitude of food prices) harms food security and lead to reduced purchasing power (Kalkuhl et al., 2016). Price control is a government regulation in limiting the price of goods and services in the market. Food price management policies carried out by 81 countries in Asia, Africa, Latin America, and the Caribbean during the food price volatility period include 1) domestic marketbased measures (released stock at the subsidized price and suspension/reduced VAT (Value Added Tax)) and other taxes, and price control or restrict private trade); 2) trade policy measures (reduction of tariffs and customs fees on imports and restricted or banned exports); 3) safety nets such as cash or food transfer; 4) increased disposable income; 5) non-market based production support (production support programs and fertilizers and seeds programs; and 6) market-based interventions (Rapallo, 2011).
Food price subsidies help the community access food. For example, India provides food subsidies on staple food commodities such as rice, millet, pulses, and vegetables which then have significantly improved food consumption (Malaiarasan et al., 2021). However, subsidizing low-nutrient staple foods (cereals, oil, and sugar) can encourage unbalanced diets and higher risk of malnutrition and health problems among the population (Food and Agriculture Organization of the United Nations, 2019).

\section{Market Development}

Food diversity in the market can be the potential mitigation to increase dietary diversity. The rapid growth of supermarkets competing with small retailers in low-income countries could encourage the consumption of cheap but less nutritious processed foods (Swinburn et al., 2019). Besides, modern markets can also provide fresh food at any time despite higher prices of goods that suit their target market. Such modern markets are easier to access than traditional markets due to the weakened purchasing power of their customers because the fuel price increases (Schipmann and Qaim, 2011; Suryadarma, 2007).

The power asymmetry of the food system needs to be addressed through policies that empower small and medium-sized farmers, local and regional markets, and short food chains. Small and medium-sized farmers and local and regional markets mostly maintain the diversity of food, e.g., vegetables, fruits, and grains that are used as the basis of traditional cuisines and diets (Swinburn et al., 2019).

Some market development interventions can be carried out in new development industries such as emerging private pharmaceuticals, food processing, and retail firms. Moreover, entrepreneurship and trade that cut long distribution chains can lower the food price (Dupouy and Gurinovic, 2020). In Indonesia, Toko Tani program becomes the government's effort to cut the food supply chain from 8-9 parties to only 3-4 parties (Food Security Agency, 2019). To achieve good food chains, infrastructure has a vital role in market access. Poor access to roads, railways, and other basic transportation will limit market access despite 
the adequate purchasing power (Thompson et al., 2014).

\section{Non-Food Based Intervention Strategy}

\section{Country's Economic Development}

Choudhury and Headey (2017) conducted a cross-country analysis related to what drives the diversification of national food supplies. Food diversification scores are closely related to the level of country's development in general, consumption per capita, and economic growth. However, in some instances, such as in rural Indonesian areas, despite economic development, the average dietary diversity of the population declined. It may occur likely due to market access (physically and economically) and perception of a healthy diet (Mehraban and Ickowitz, 2021).

Other economic development factors that influence food diversification scores are the transition of population structure (younger to older), urbanization, and increased dependence on the food trade. Research showed that high levels of population density are negatively associated with food diversification scores (Choudhury and Headey, 2017). The relationship between food diversification and urbanization could occur due to increasing reliance on food trade. In some cases, urbanization does not affect increasing food diversification due to low incomes and the transition of food choices to high sugar food and instant food (Pandey et al., 2020).

\section{Social Behavior Changes and Communication}

Social behavior changes and communication (SBCC) become one of the public health interventions that significantly improve health status. It is a systematic approach of interactive, theory-based, and research-driven communication strategies to change individual behaviors and social norms (USAID Wildlife Asia, 2020).

SBCC in the field of nutrition have widely been performed to increase the community's dietary diversity. The approach includes school feeding programs, general food assistance, and other nutrition-sensitive programs. It is also broadcasted to various channels such as community radio shows, television programs, caregiver support groups, and policy-level working groups (World Food Programme, 2020).

Education has strong and significant effects on household dietary diversity and child nutrition (Chegere and Stage, 2020). Educational and social marketing activities are critically aimed at increasing the consumption of micronutrientrich food (Thompson et al., 2014). Communitybased nutrition education with a participatory approach for caregivers can increase children's dietary diversity even in areas with food insecurity (Kuchenbecker et al., 2017). Another example of participatory community approach is that community health workers (CHW) through small neighborhood units (SNU) likely improve dietary diversity and child nutrition practices by and caregiver attitudes towards recommended feeding (Hitachi et al., 2020).

The Farmer Nutrition School (FNS) program for mothers and children in the first 1,000 days in Bangladesh demonstrated a significant increase in food diversity consumption because of education and consultation related to nutrition, water, sanitation, and hygiene (WASH), and agriculture (Strengthening Partnerships, Results, and Innovations in Nutrition Globally (SPRING), 2017). Apart from crop and livestock diversity, purchasing power, infrastructure, supply, and price stability, well-run food system for dietary diversity could improve cultural norms. Cultural norms will affect food allocation and dietary diversity at household and community levels (Thompson et al., 2014).

\section{Cash and Voucher Programs}

Direct cash transfers can impact nutrition status through nutrition-sensitive channels such as improved food diversity and food consumption for all household members. Cash transfers are one of the social protection interventions aimed at increasing and stabilizing household income (Food and Agriculture Organization of the United Nations, 2020).

Both conditional and unconditional transfers could improve the diversity of food recipients (Grellety et al., 2017; Grijalva-Eternod et al., 2018; Harris-Fry et al., 2018; Irenso and Atomsa, 2018; Potts et al., 2019; Cahyadi et al., 2018; Martins and Monteiro, 2016). Conditional cash transfers 
are available when the beneficiary must meet certain conditions. Meanwhile, unconditional cash transfers are available anytime for the beneficiary that must be at below the poverty standard (World Bank, 2018).

In contrast to cash transfers, voucher schemes allow beneficiaries to exchange paper or electronic cards for goods and services at pre-selected stores. Meanwhile, food transfers are almost the same as cash transfers but provide food exchange (Food and Agriculture Organization of the United Nations, 2016). Both interventions have a positive effect on food diversity. In Ethiopia, the provision of cash transfers resulted in better household dietary diversity than those who received food only due to an ongoing increase in food prices (Baye et al., 2014). While in Northern Ecuador, vouchers gave the most significant effect on increasing dietary diversity compared to cash transfers and food transfers. Vouchers give households the ability to consume a variety of food on a longer period and to buy cheaper food (Hidrobo et al., 2014).

\section{Mass Media Campaign}

Mass media campaign for behavior change related to healthy eating behavior is a method to provide education to large populations. Positive behavior changes occurred due to this mass campaign (Korda and Itani, 2013; Wakefield et al., 2010). Mass media communications in India $\mathrm{p}$ could increase the intake of vitamin A-rich foods among preschool children by fourfold. It was then followed by improved knowledge, attitudes, and practices on vitamin A food consumption among mothers of preschool children (Nayak et al., 2001). Several mass media platforms that can serve as campaign platforms include television, radio, newspaper, magazines, posters, leaflets, and internet media (website, emails, podcasts, and blogs). Another highly developed method is internet communication using social media, such as Tiktok, Youtube, Twitter, Facebook, and Instagram (Haslam et al., 2019; Korda and Itani, 2013; Maryon-Davis, 2012; Saei et al., 2021; Santarossa and Woodruff, 2018; Zhu et al., 2020).

Health promotion must uplift health information to the public, social marketing (engaging and motivating people to adopt a healthy lifestyle), and media advocacy (raising awareness of health topics to change policies in facilitating health promotion) (Maryon-Davis, 2012).

Food-based and non-food-based interventions are interconnected to improve dietary diversity. For example, poor management of food production and supply can affect food availability such as food price inflation, which reduces the community purchasing power. The provision of nutrition education and cash transfers will not be sufficient to overcome this problem because the community has inadequate access to food. Therefore, the government should carry out all interventions involving the community and multisectoral participation to achieve dietary diversity.

Above all, none of the existing research compares the effectiveness of all programs to improve dietary diversity. None examines the success of the food-based dietary guidelines program alone to improve dietary diversity.

\section{CONCLUSION}

Intervention and policy to increase individual and population dietary diversity are closely related to understanding of problems and their causes. Intervention policies are categorized as food-based interventions and non-food-based interventions. Food-based interventions take parts in handling of the food system, such as food production and supply management, agriculture diversity, foodbased guidelines, food price controls, and market development. Non-food-based interventions can be done by improving economic aspect, social and behavior change communication, cash transfer, and mass media campaigns.

These interventions are expected to address the basic causes of malnutrition because of insufficient food diversity consumption at individual and population levels. There is no single policy that can replace other policies in improving dietary diversity. Therefore, it is imperative that all policies, both food-based and non-food-based interventions, must be simultaneously implemented to improve dietary diversity.

\section{ACKNOWLEDGMENT}

We would like to thank the Faculty of Public Health, Universitas Airlangga and Nutrition 
Study Program, the State University of Medan for supporting the research.

\section{REFERENCES}

Agrawal, S., Fledderjohann, J., Vellakkal, S., \& Stuckler, D. (2015). Adequately diversified dietary intake and iron and folic acid supplementation during pregnancy is associated with reduced occurrence of symptoms suggestive of pre-eclampsia or eclampsia in Indian women. PLoS ONE 10, e0119120. doi:10.1371/journal. pone.0119120

Ambikapathi, R., Gunaratna, N.S., Madzorera, I., Passarelli, S., Canavan, C.R., Noor, R.A., \& Fawzi, W.W. (2019). Market food diversity mitigates the effect of environment on women's dietary diversity in the Agriculture to Nutrition (ATONU) study, Ethiopia. Public Health Nutr. 22, 2110-2119. https://doi.org/10.1017/ S136898001900051X

Arimond, M., Wiesmann, D., Becquey, E., Carriquiry, A., Daniels, M., Deitchler, M., \& Torheim, L.E., (2011). Dietary Diversity as a Measure of the Micronutrient Adequacy of Women's Diets in Resource-Poor Areas: Summary of Results from Five Sites 97.

Baye, K., Retta, N., \& Abuye, C., (2014). Comparison of the effects of conditional food and cash transfers of the ethiopian productive safety net program on household food security and dietary diversity in the face of rising food prices: ways forward for a more nutritionsensitive program. Food Nutr. Bull. 35, 289295. doi:10.1177/156482651403500301

Cahyadi, N., Rema, H., Benjamin, A., Prima, O., R. A., Satriawan, E., \& S. Ekki, (2018). Cumulative Impacts of Conditional Cash Transfer Programs: Experimental Evidence from indonesia.

Chegere, M.J., Stage, J., (2020). Agricultural production diversity, dietary diversity and nutritional status: Panel data evidence from Tanzania. World Dev. 129, 104856. doi:10.1016/j.worlddev.2019.104856

Chiang, S.-N., \& Capiña, X.G., (2018). Adding Diversity as a New Dimension in the Food Security Framework. Southeast Asian Reg. Cent. Grad. Study Res. Agric. SEARCA 12.

Choudhury, S., \& Headey, D., (2017). What drives diversification of national food supplies? A cross-country analysis. Glob. Food Secur. 15, 85-93. doi:10.1016/j.gfs.2017.05.005
Cordero-Ahiman, O.V., Vanegas, J.L., FrancoCrespo, C., Beltrán-Romero, P., Quinde-\& Lituma, M.E., (2021). Factors that determine the dietary diversity score in rural households: The Case of the Paute River Basin of Azuay Province, Ecuador. Int. J. Environ. Res. Public. Health 18, 2059. doi: 10.3390/ijerph18042059

Custodio, E., Herrador, Z., Nkunzimana, T., Węziak-Białowolska, D., Perez-Hoyos, A., \& Kayitakire, F., (2019). Children's dietary diversity and related factors in Rwanda and Burundi: A multilevel analysis using 2010 Demographic and Health Surveys. PLOS ONE 14, e0223237. doi:https://doi.org/10.1371/ journal.pone. 0223237

Dillon, A., McGee, K., \& Oseni, G., (2015). Agricultural Production, Dietary Diversity and Climate Variability. J. Dev. Stud. 51, 976-995. doi:10.1080/00220388.2015.1018902

Dorward, A., (2014). How can agricultural interventions contribute in improving nutrition health and achieving the MDGs in LeastDeveloped Countries? Nestlé Nutr. Inst. Workshop Ser. 78, 93-109. doi:10.1159/000354946

Dulloo, M.E., (2019). Maintaining Diversity of Plant Genetic Resources as a Basis for Food Security, in: Ferranti, P., Berry, E.M., Anderson, J.R. (Eds.), Encyclopedia of Food Security and Sustainability. Elsevier, Oxford, pp. 54-63. doi: 10.1016/B978-0-08-100596-5.22208-7

Dupouy, E., \& Gurinovic, M. (2020). Sustainable food systems for healthy diets in Europe and Central Asia: Introduction to the special issue. Food Policy 101952. doi: 10.1016/j. foodpol.2020.101952

D’Souza, A., \& Jolliffe, D. (2016). Coping with Food Price Shocks in Afghanistan, in: Kalkuhl, M., von Braun, J., Torero, M. (Eds.), Food Price Volatility and Its Implications for Food Security and Policy. Springer International Publishing, Cham, pp. 543-581. doi:10.1007/978-3-31928201-5_21

Farhangi, M.A., \& Jahangiry, L. (2018). Dietary diversity score is associated with cardiovascular risk factors and serum adiponectin concentrations in patients with metabolic syndrome. BMC Cardiovasc. Disord. 18, 68. doi: 10.1186/ s12872-018-0807-3

Food Security Agency (2018). Annual Report of the Food Security Agency.

Food Security Agency, (2019). Food Security Development Policies and Programs in 2020. 
Food Security Agency, (2021). Food Security Agency Performance Report 2020.

Food and Agriculture Organization of the United Nations, (2016). Cash and voucher programmes.

Food and Agriculture Organization of the United Nations, (2019). The State of Food Security and Nutrition in the World 2019: Safeguarding against economic slowdowns and downturns. Food \& Agriculture Org.

Food and Agriculture Organization of the United Nations, (2020). Nutrition and cash-based interventions. FAO. doi: 10.4060/ca9143en

Food and Agriculture Organization of the United Nations, (2021). Food-based Dietary Guidelines [WWW Document]. Food Agric. Organ. U. N. Retrieved from http://www.fao.org/nutrition/ education/food-dietary-guidelines/home/en/ (accessed 7.21.21).

Food and Agriculture Organization, IFAD, UNICEF, WFP, (2020). The State of Food Security and Nutrition in the World 2020. Transforming food systems for affordable healthy diets. FAO.

Geng, S., Ma, J., Liu, S., \& Zhang, J. (2018). Lack of Dietary Diversity Contributes to the Gaps in Micronutri- ent Status and Physical Development between Urban and Rural Infants. Iran J Public Health 47, 9.

Grellety, E., Babakazo, P., Bangana, A., Mwamba, G., Lezama, I., Zagre, N.M., \& Ategbo, E.-A., (2017). Effects of unconditional cash transfers on the outcome of treatment for severe acute malnutrition (SAM): a cluster-randomised trial in the Democratic Republic of the Congo. BMC Med. 15, 87. doi: 10.1186/s12916-017-0848-y Grijalva-Eternod, C.S., Jelle, M., HaghparastBidgoli, H., Colbourn, T., Golden, K., \& Seal, A.J., (2018). A cash-based intervention and the risk of acute malnutrition in children aged 6-59 months living in internally displaced persons camps in Mogadishu, Somalia: Anon-randomised cluster trial. PLoS Med. 15, e1002684. doi: 10.1371/journal.pmed.1002684

Habtemariam, L.T., Gornott, C., Hoffmann, H., \& Sieber, S., (2021). Farm Production Diversity and Household Dietary Diversity: Panel Data Evidence From Rural Households in Tanzania. Front. Sustain. Food Syst. 0. doi: 10.3389/ fsufs.2021.612341

Harris-Fry, H.A., Paudel, P., Harrisson, T., Shrestha, N., Jha, S., Beard, B.J., \& Saville, N.M., (2018). Participatory women's groups with cash transfers can increase dietary diversity and micronutrient adequacy during pregnancy, whereas women's groups with food transfers can increase equity in intrahousehold energy allocation. J. Nutr. 148, 1472-1483. doi: 10.1093/jn/nxy109

Haslam, K., Doucette, H., Hachey, S., MacCallum, T., Zwicker, D., Smith-Brilliant, M., \& Gilbert, R., (2019). YouTube videos as health decision aids for the public: An integrative review. Can. J. Dent. Hyg. CJDH J. Can. Hyg. Dent. JCHD 53, 53-66.

Heiman, M.L., Greenway, F.L., 2016. A healthy gastrointestinal microbiome is dependent on dietary diversity. Mol. Metab. 5, 317-320. doi: 10.1016/j.molmet.2016.02.005

Hidrobo, M., Hoddinott, J., Peterman, A., Margolies, A., \& Moreira, V., (2014). Cash, food, or vouchers? Evidence from a randomized experiment in northern Ecuador. J. Dev. Econ. 107, 144-156. doi:/10.1016/j. jdeveco.2013.11.009

Hitachi, M., Wanjihia, V., Nyandieka, L., Francesca, C., Wekesa, N., Changoma, J., \& Kaneko, S. (2020). Improvement of dietary diversity and attitude toward recommended feeding through novel community based nutritional education program in Coastal Kenya-An Intervention Study. Int. J. Environ. Res. Public. Health 17, 7269. doi: 10.3390/ijerph17197269

Irenso, A.A., \& Atomsa, G.E., (2018). Implications of Ethiopian Productive Safety Net Programme on household dietary diversity and women's body mass index: a cross-sectional study. Food Nutr. Res. 62. doi: 10.29219/fnr.v62.1574

Kalkuhl, M., von Braun, J., \& Torero, M., (2016). Volatile and Extreme Food Prices, Food Security, and Policy: An Overview, in: Kalkuhl, M., von Braun, J., Torero, M. (Eds.), Food Price Volatility and Its Implications for Food Security and Policy. Springer International Publishing, Cham, pp. 3-31. doi: 10.1007/978-3-31928201-5_1

Kennedy, G., Ballard, T., \& Dop, M.-C. (2011). Guidelines for measuring household and individual dietary diversity. FAO, Rome.

Kissoly, L.D., Karki, S.K., \& Grote, U. (2020). Diversity in Farm Production and Household Diets: Comparing Evidence From Smallholders in Kenya and Tanzania. Front. Sustain. Food Syst. 4. https://doi.org/10.3389/fsufs.2020.00077

Korda, H., \& Itani, Z. (2013). Harnessing Social Media for Health Promotion and Behavior Change. Health Promot. Pract. 14, 15-23. doi: $10.1177 / 1524839911405850$ 
Kuchenbecker, J., Reinbott, A., Mtimuni, B., Krawinkel, M.B., \& Jordan, I. (2017). Nutrition education improves dietary diversity of children 6-23 months at community-level: Results from a cluster randomized controlled trial in Malawi. doi: PLOS ONE 12, e0175216. https://doi. org/10.1371/journal.pone.0175216

Laitinen, K., \& Mokkala, K. (2019). Overall dietary quality relates to gut microbiota diversity and abundance. Int. J. Mol. Sci. 20, 1835. doi:10.3390/ijms20081835

Malaiarasan, U., Paramasivam, R., \& Felix, K.T., (2021). Does Food Price Subsidy Affect Dietary Diversity? Evidence from South India. Margin J. Appl. Econ. Res. 15, 268-290. doi: $10.1177 / 0973801021990397$

Martins, A.P.B., \& Monteiro, C.A. (2016). Impact of the Bolsa Família program on food availability of low-income Brazilian families: a quasi experimental study. BMC Public Health 16, 827. doi: 10.1186/s12889-016-3486-y

Maryon-Davis, A. (2012). Using the Mass Media to Promote Health. InnovAiT 5, 767-773. doi: 10.1093/innovait/ins191

Masters, W., Bai, Y., Herforth, A., Sarpong, D., Mishili, F., Kinabo, J.,... Coates, J., (2018). Measuring the Affordability of Nutritious Diets in Africa: Price Indexes for Diet Diversity and the Cost of Nutrient Adequacy. Am. J. Agric. Econ. 100, 1285-1301. doi: https://doi. org/10.1093/ajae/aay059

Matita, M., Chirwa, E.W., Johnston, D., Mazalale, J., Smith, R., \& Walls, H., (2021). Does household participation in food markets increase dietary diversity? Evidence from rural Malawi. Glob. Food Secur. 28, 100486. doi: 10.1016/j. gfs.2020.100486

Mehraban, N., \& Ickowitz, A. (2021). Dietary diversity of rural Indonesian households declines over time with agricultural production diversity even as incomes rise. Glob. Food Secur. 28, 100502. doi:10.1016/j.gfs.2021.100502

Morón, C., (2006). Food-based nutrition interventions at community level. Br. J. Nutr. 96 Suppl 1, S20-22. doi: https://doi.org/10.1079/ bjn20061693

Nair, M.K., Augustine, L.F., \& Konapur, A., (2016). Food-Based Interventions to Modify Diet Quality and Diversity to Address Multiple Micronutrient Deficiency. Front. Public Health 3. doi: 10.3389/fpubh.2015.00277

Nannipieri, P., Kandeler, E., \& Ruggiero, P., (2002). Enzyme activities and microbiological and biochemical processes in soil. Enzym. Environ. Act. Ecol. Appl. 1-33.

Nayak, M.U., Vazir, S., Vijayaraghavan, K., \& Chandralekha, K. (2001). Nutrition Communication Using Social-Marketing Techniques to Combat Vitamin A Deficiency: Results of Summative Evaluation. Food Nutr. Bull. 22, 454-465. doi: 10.1177/156482650102200419

Nithya, D.J., \& Bhavani, R.V. (2018). Dietary Diversity and Its Relationship with Nutritional Status among Adolescents and Adults in Rural India. J. Biosoc. Sci. 50, 397-413. doi: 10.1017/ S0021932017000463

Obayelu, O.A., \& Osho, F.R., (2020). How diverse are the diets of low-income urban households in Nigeria? J. Agric. Food Res. 2, 100018. doi: 10.1016/j.jafr.2019.100018

Oldewage-Theron, W.H., \& Kruger, R., (2008). Food Variety and Dietary Diversity as Indicators of the Dietary Adequacy and Health Status of an Elderly Population in Sharpeville, South Africa. J. Nutr. Elder. 27, 101-133. doi: 10.1080/01639360802060140

Otsuka, R., Nishita, Y., Tange, C., Tomida, M., Kato, Y., Nakamoto, M., ... Shimokata, H., (2017). Dietary diversity decreases the risk of cognitive decline among Japanese older adults. Geriatr. Gerontol. Int. 17, 937-944. https://doi. org/10.1111/ggi.12817

Pandey, B., Reba, M., Joshi, P.K., Seto, K.C., (2020). Urbanization and food consumption in India. Sci. Rep. 10, 17241. doi: 10.1038/ s41598-020-73313-8

Potts, K.S., Mulugeta, A., \& Bazzano, A.N., (2019). Animal Source Food Consumption in Young Children from Four Regions of Ethiopia: Association with Religion, Livelihood, and Participation in the Productive Safety Net Program. Nutrients 11. doi: 10.3390/ nu11020354

Powell, B., Bezner Kerr, R., Young, S.L., \& Johns, T. (2017). The determinants of dietary diversity and nutrition: ethnonutrition knowledge of local people in the East Usambara Mountains, Tanzania. J. Ethnobiol. Ethnomedicine 13, 23. doi:10.1186/s13002-017-0150-2

Rapallo, R., (2011). Food Price Volatility and the Right to Food.

Roesler, A.L., S mithers, L.G., Wangpakapattanawong, P., Moore, V., (2019). Stunting, dietary diversity and household food insecurity among children under 5 years 
in ethnic communities of northern Thailand. J. Public Health 41, 772-780. doi: 10.1093/ pubmed/fdy201

Saei, M.H., Valadi, S., Karimi, K.,\& Khammarnia, M. (2021). The role of mass media communication in public health: The impact of Islamic Republic of Iran broadcasting health channel on health literacy and health behaviors. Med. J. Islam. Repub. Iran 35, 54. doi:10.47176/mjiri.35.54

Santarossa, S., \& Woodruff, S.J., (2018). \#LancerHealth: Using Twitter and Instagram as a tool in a campus wide health promotion initiative. J. Public Health Res. doi:10.4081/ jphr.2018.1166

Schipmann, C., \& Qaim, M. (2011). Modern Food Retailers and Traditional Markets in Developing Countries: Comparing Quality, Prices, and Competition Strategies in Thailand. Appl. Econ. Perspect. Policy 33, 345-362.

Strengthening Partnerships, Results, and Innovations in Nutrition Globally (SPRING), (2017). Bangladesh: Farmer Nutrition School Cohort Study. Sustainability of Improved Practices Following Graduation - Technical Brief. 12.

Suryadarma, D. (Ed.), (2007). Impact of supermarkets on traditional markets and retailers in Indonesia's urban centers: research report, SMERU research report. SMERU Research Institute, Jakarta.

Swinburn, B.A., Kraak, V.I., Allender, S., Atkins, V.J., Baker, P.I., Bogard, J.R., ... Dietz, W.H., (2019). The Global Syndemic of Obesity, Undernutrition, and Climate Change: The Lancet Commission report. The Lancet 393, 791-846. https://doi.org/10.1016/S01406736(18)32822-8

Talukder, A., Haselow, N.J., Osei, A.K., Villate, E., Reario, D., Kroeun, H., ... Quinn, V., (2010). Homestead food production model contributes to improved household food security and nutrition status of young children and women in poor populations. Field Actions Sci. Rep. J. Field Actions.

Thompson, B., Amoroso, L., C.A.B. International, Food and Agriculture Organization of the United Nations, (2014). Improving diets and nutrition: food-based approaches. CABI ; Food and Agriculture Organization of the United Nations, Wallingford, Oxfordshire : Rome, Italy.

USAID Wildlife Asia, (2020). Social and Behavior Change Communication (SBCC) Demand Reduction Guidebook.
Utami, N.H., Mubasyiroh, R., (2020). Keragaman Makanan dan Hubungannya dengan Status Gizi Balita: Analisis Survei Konsumsi Makanan Individu (SKMI). GIZI Indones. 43, 37. doi: 10.36457/gizindo.v43i1.467

Valdes, A.M., Walter, J., Segal, E., Spector, T.D., 2018. Role of the gut microbiota in nutrition and health. BMJ 361, k2179. doi: 10.1136/ bmj.k2179

Verger, E.O., Ballard, T.J., Dop, M.C., Martin-\& Prevel, Y., (2019). Systematic review of use and interpretation of dietary diversity indicators in nutrition-sensitive agriculture literature. Glob. Food Secur. 20, 156-169. doi: 10.1016/j. gfs.2019.02.004

WFP, (2020). Nutrition in Numbers: Beyond the Annual Perfomance Report 2019 Series. An overview of WFP nutrition programming in 2019.

Wakefield, M.A., Loken, B., \& Hornik, R.C., (2010). Use of mass media campaigns to change health behaviour. Lancet 376, 1261-1271. doi: 10.1016/S0140-6736(10)60809-4

World Bank, (2018). The State of Social Safety Nets.

World Health Organization, (1998). Preparation and use of food-based dietary guidelines: report of a Joint FAO/WHO Consultation, WHO Technical Report Series. WHO, Geneva.

World Health Organization, (2011). Regional Consultation on Food-Based Dietary Guidelines for countries in the Asia Region: A Report.

Yin, Z., Fei, Z., Qiu, C., Brasher, M.S., Kraus, V.B., Zhao, W., .. Zeng, Y. (2017). Dietary Diversity and Cognitive Function among Elderly People: A Population-Based Study. J. Nutr. Health Aging 21, 1089-1094. doi: 10.1007/s12603017-0912-5

Zerfu, T.A., Umeta, M., \& Baye, K., (2016). Dietary diversity during pregnancy is associated with reduced risk of maternal anemia, preterm delivery, and low birth weight in a prospective cohort study in rural Ethiopia. Am. J. Clin. Nutr. 103, 1482-1488. doi: 10.3945/ ajen.115.116798

Zhang, J., Zhao, A., Wu, W., Yang, C., Ren, Z., Wang, M., ... Zhang, Y., (2020). Dietary Diversity Is Associated With Memory Status in Chinese Adults: A Prospective Study. Front. Aging Neurosci. 0. https://doi.org/10.3389/ fnagi.2020.580760 
Zheng, J., Zhou, R., Li, F., Chen, L., Wu, K., Huang, J., ... Wu, X. (2021). Association between dietary diversity and cognitive impairment among the oldest-old: Findings from a nationwide cohort study. Clin. Nutr. 40, 1452-1462. doi: 10.1016/j. clnu.2021.02.041

Zhu, C., Xu, X., Zhang, W., Chen, J., \& Evans, R., (2020). How Health Communication via Tik Tok Makes a Difference: A Content Analysis of Tik Tok Accounts Run by Chinese Provincial Health Committees. Int. J. Environ. Res. Public. Health 17, 192. doi: 10.3390/ijerph17010192 van der Vorst, J., da Silva, C., Trienekens, J., Rural Infrastructure and Agro-Industries Division, (2007). Agro-industrial supply chain management: concepts and applications, Agricultural management, marketing and finance occasional paper. FAO, Rome, Italy. 